\title{
Learning Strategies Employed in English Language: Perceptions and Practices
}

Pitambar Paudel

\begin{abstract}
Learning strategies are the key tools to determine the approach for achieving the learning goal. They are included in different phases of teaching learning process. They are usually tied to the needs and interests of students to enhance their learning efficiency. This article aims at exploring perspectives and practices of learning strategies in learning English language. For this, phenomenological descriptive qualitative research was conducted with a class of 48 students of Bachelor in education at a constituent campus, under Tribhuvan University, Nepal. Both the class of the students and campus were selected purposively to meet the requirement of phenomenological study. Thirty classes were observed as a participant as well as teacher and from the same group of the students only ten students were interviewed. Then, the data from both the sources were triangulated, interpreted and analyzed descriptively. From this study, it was interpreted that students employed various strategies to learn different language skills and aspects. The study revealed that students felt difficulty in selecting proper learning strategy for learning grammatical rules due to many exceptional cases and listening skill due to their less time devotion on it while the felt ease to select and employ proper strategies in learning vocabulary.
\end{abstract}

Keywords: cognitive, communicative, metacognitive, organization, rehearsal

\section{Introduction}

Language learning is the process of internalizing a language, either a mother tongue or a foreign language. Learning a language means being competent in manipulating the four basic language skills; listening, speaking, reading and writing and various aspects of language. To get mastery over these language skills, a learner uses his/her personal approaches which are termed as learning strategies. Learning strategies determine the approach for achieving the learning objectives and are included in the pre-instructional activities, information presentation, learning activities, testing and so on. Jimenez (2018) concedes that strategies are usually tied to and determined on the levels, needs, interests, background of students and cultural context of teaching and learning.

A learning strategy is a person's approach to learning and using information for boosting up personal efficiency and ability in language use. Students use learning strategies for understanding information and solving language related problems. Rubin (1987) defines learning strategies as "any sets of operations, steps, plans, routines used by the learner to facilitate the obtaining, storage, retrieval and use of information" (p. 19). Language learning strategies are attempts to develop linguistic, communicative, discourse and sociolinguistic competences in the target language that is by employing various and appropriate learning strategies they can enhance all round growth and development in language and language use. In this backdrop, Richards, Platt and Platt(1992) state that learning strategies are "intentional behavior and thoughts used by learners during learning so as to better help them understand, learn or remember new 
information"(p. 209). Similarly, Stern (1992) concedes "the concept of learning strategy is dependent on the assumption that learners consciously engage in activities to achieve certain goals and learning strategies can be regarded as broadly conceived intentional directions and learning techniques"(p. 261). Learning strategy in language learning is a way in which a learner attempts to work out the meanings and uses of words, grammatical rules and other aspects of a language, for example, by the use of generalization and inference. Tay (2013) concedes that learning strategies are the total effort that students need to process, understand and adopt the information introduced in learning and teaching process or in their individual preparation. Similar to him, Kafadar ( 2013 a) argues that the whole of the performed activities of learners to give meaning to information in cognitive and affective processes are the learning strategies. Learning strategies are the quick and tactic techniques that learners use to improve or construct their knowledge. In this vein, Kalati (2016) asserts that conscious and semi conscious thoughts and behaviours employed by the learners to improve their knowledge and understanding of a target language are learning strategies which can be unique to each other.

They are effective and efficient techniques used for getting new information, connecting it to the given information and use it to learn and consolidate with the current knowledge. The shift within the field of language learning over the last twenty years with greater emphasis being put on learners and learning rather than on teachers and teaching. In parallel to this new shift of interest, how learners process new information and what kinds of strategies they employ to understand learning and remember the information, have been the primary concern of the researchers who are dealing with the field of foreign/second language learning and teaching.

Accessing and accommodating students' learning strategies is a complex job as each individual adopts different and in some cases unique strategies. However, an instructional designer or the teacher needs to be aware of the strategies that students select and use in the classroom learning. $\mathrm{Gu}(2005)$ in this context, argues that it is difficult to find out and it is not clear about the bases of selecting particular strategies and preference on them rather than others. In this vein, Simsek and Balaban(2010) urge not to feel surprise looking various strategies employed by the students because each student is guided by instructional variables like technology, exposure, time, teaching methods, subject matters, feedback, individual differences, evaluation system and so forth.

From the aforementioned discourse, it can be said that language learning strategy is any action that language learners perform in order to increase their target language proficiency. It may focus on some quite specific task, for example, the learning of an item of vocabulary or the memorization of a grammatical rule. Alternatively, it may have to do with the language learning process in general. For example, learners may decide to organize their vocabulary noted in a particular way, or to evaluate themselves at regular intervals in order to identify aspects or their proficiency that need special attention.

Since language classroom is like a problem solving environment in which language learners are likely to face new input and difficult tasks given by their teachers, learners attempts to find the quickest or easiest way to do what is required, that is, use of language learning strategies to get mastery over language problem is inescapable. Thus, this research attempts to explore the perception and practices of the learning strategies that learners employ in learning English language. 


\section{Review of Literature}

Though the studies and practices on learning strategies began in 1960s, the formal elaboration and exploration of them started with the publication of papers collectively known as the good language learner by Rubin in 1975(as cited in Larsen Freeman, 2008, p.159). Since then, hundreds of studies have been generated that look at different aspects of learning strategies and their roles in language learning. Regarding the beginning of learning strategies, Larsen-freeman (2008) states:

Keeping with the perception that language learners were seen to be more actively responsible for their learning, Rubin investigated where good language learners did to facilitate their learning. From this investigation, she identified some of their learning strategies, the techniques or devices which learners may use to acquire knowledge (p. 159)

Good language learners are willing and accurate guessers who have strong desires to communicate and will attempt to do so even at the risk of appearing foolish (Rubin ,1975 as cited in Larsen Freeman, 2008, p.159).

From the aforementioned literature, it is found that researches into language learning strategies began in the 1960s, particularly; development in cognitive psychology influenced much of the researches done on language learning strategies. The primary concern in most of the researches has been on identifying what good language learners report they do to learn a second or foreign language. In 1966, Aaron Carton published his study entitled The Method of Inference in Foreign Language Study, which was the first attempt on learners' strategies. After Carton in 1971, Rubin (1975) started doing research focusing on the strategies of successful learners and stated that, once identified; such strategies could be made available to less successful learners. Rubin(1987) O'malley (1985),Oxford(1990), Brown(2002;2006), and Simsek $(2006 ; 2010)$ have greatly contributed in the classification and promotion of language learning strategies. Language learning strategies are remaining as active areas of research at present among the researchers. Despite extensive researches by various researchers, many theoretical and practical issues are needed to be addressed (as cited in Hismanoglu, 2000).

Learners use learning strategies to help them understand information and solve problems related to language. Students who do not know or use good learning strategies often learn passively and ultimately fail in language. Learning strategy focuses on making students more active by teaching them how to learn and how to use what they have learned to be successful in their lifelong learning process. By getting mastery over language through the use of appropriate learning strategies, they can prepare themselves to cope with any challenges in the language use and they learn how to live with language in the world.

\section{Classification of Learning Strategies}

Since learning strategies are unique to individual they have been classified differently by the scholars. In this vein, O'Malley(1985) classifies meta cognitive strategies, cognitive strategies and socio affective strategies as the learning strategies that learners employ in learning second language (as cited in Brown, 1994, pp. 116-117).

Metacognitive Strategies are used to express executive function. The strategies are required for 
planning, learning, thinking about the learning process as it is taking place, monitoring of one's production or comprehension and evaluating learning after an activity is completed.(O'Maly,1985 as cited in Brown, 1994, p. 116).

Cognitive strategies are more specific to learning tasks and they involve more direct manipulation of the learning materials itself. Repetition, resorting, translation, note taking, contextualization elaboration are the most important cognitive strategies. (O’Maly, 1985 as cited in Brown, 1994, pp. 116-117). Similarly,the strategies which are related with social-mediating activity and transacting with others are socio-affective strategies. Co-operation, questions for clarification are the examples of cognitive strategies( O’Maly,1985 as cited in Brown, 1994, p. 117).

In the same vein, Rubin (1987) classifies learning strategies, communicative strategies, and social strategies as the major categories of learning strategies employed by learners which contribute directly or indirectly for effective and sustainable language learning. Learning strategies are those which directly contribute to the development of the language system constructed by the learners. Cognitive learning strategies and Metacognitive are the two types of learning strategies.( Rubin ,1987).

Cognitive learning strategies refer to the steps or operations used in learning or problem solving that requires direct analysis, transformation, and synthesis of learning items. Rubin (1987) identifies classification/verification, guessing/inductive inference, deductive reasoning, practice, memorization and monitoring as the main cognitive learning strategies (pp. 41-51). Rubin (1987) concedes that metacognitive learning strategies are used to oversee regular or self direct language learning.

Communicative language learning strategies focus on the process of participating in a conversation and getting the contextual meaning that the speaker has intended. The speakers use these strategies when they face some complexities due to the fact that their communication is misunderstood by the co-speaker. Similarly, social strategies are those activities or processes which afford the opportunities to be exposed to and practice their knowledge. Although these strategies provide ample exposure to the target language, they contribute indirectly to learning since they do not lead directly to obtaining, storing, retrieving, and using of language (Rubin, 1987).

Oxford (1990) categorizes direct and indirect as the basic types of learning strategies. Making comments on her classification Brown (1994) states that she sees the aim of language learning strategies as being oriented towards the development of communicative competence and has outlined a host of learning and communication strategies that have been successful among the learners( pp. 125-127).

Directive strategies lead direct contribution to the obtaining, storing, retrieving and using of the language to the learners in learning language. Directive strategies include memory strategy, cognitive strategy and compensation strategy ( Oxford ,1990).

Memory strategies deal with grouping, associating, using imagery, representing sounds in memory, using physical response or sensation, using mechanical techniques, semantic mapping, etc. Memory strategies include creating mental linkages, applying image and sounds, reviewing well and employing action Cognitive strategies involve the identification, retention and retrieval of language elements. ( Oxford, 1990). 
Similarly, cognitive strategies include practicing, receiving and sending massages, analyzing and reasoning and creating structure for input and output. Likewise, compensation strategies deal with using linguistic and nonlinguistic clues, switching to the mother tongue, selecting topic, words, etc. It incorporates guessing intelligently and overcoming limitations in speaking and writing ( Oxford, 1990).

Oxford (1990) concedes that indirect strategies do not provide direct contribution to the obtaining, storing, retrieving of language, but they provide ample exposure and opportunities to the target language. Oxford(1990) incorporates metacognitive, affective and social strategies under indirect strategy.

Similar to Rubin's (1975) claim, Oxford( 1990) argues that metacognitive strategies deal with planning, monitoring and evaluating language learning activities. For example, students may develop a plan for monitoring their progress by constantly comparing their current level of proficiency with the course goals outlined in the curriculum. This strategy incorporates centering, arranging, planning and evaluating learners' learning.

Affective strategies on the other hand are those that serve to regulate emotions, attitudes, and motivation. For example, students may read linguistically simplified books to develop a positive attitude towards reading materials. Affective learning strategies include, lowering anxiety, self encouraging and taking self emotional temperature (as cited from Oxford, 1990).

Social strategies are those actions that learners use to interact with users of the language. For example, students may deliberately seek out opportunities to use target language with native speakers of the language. Oxford (1990) states that asking questions, cooperating and empathizing with others come under social strategies

In oxford's (1990) system, metacognitive strategies are concerned with the learner's emotional requirements such as confidence while social strategies lead to increase interaction with the target language. Cognitive strategies are the mental strategies that learners use to make sense of their learning. Memory strategies and compensation strategies help learners overcome knowledge gaps to continue the communication.

On the basis of learning strategies employed, Brown (2002) identifies visual, analytical, auditory and impulsive as the types of learners ( as cited from Jimenez,2018, p.75). In the backdrop of learning strategies, Brown (2006) discusses repetition, memorization, formulaic expression, verbal attention getter, answer in unison, talk to self, elaboration, anticipatory answer, monitoring, appeal for assistance, request for classification and role play as the basic learning strategies that learners use in learning second language. Simek (2006) explains rehearsal, elaboration, organization, metacognition, motivational and cognitive strategies along with the various activities associated with them.

\section{Benefits of Learning Strategies}

Language learning strategy is a methodological innovation. Since the amount of information to be processed by language learners is demanding in language classroom, learners use different learning strategies in performing the tasks and processing the new input they encounter with. Learning strategies are the good indicators of how learners approach the problems that they encountered during the process of language learning. They help the learners understand information and solve the problems. Learning 
strategies focus on making students more active learners by teaching them how to learn and how to use what they have learned to be successful. Similarly, teachers are helped by giving valuable ideas and clues about how their students asses the situation, plan, select appropriate skills so as to understand, learn or remember new input presented in the language classroom.

Learning strategies can help students to face up to the emotional difficulties and to overcome them by drawing attention to the potential frustrations or pointing them out as they arise. Fedderholdt (1997) states that the language learning strategies can appropriately improve learner's language skills in a better way (as cited in Hismanoglu, 2000). They are beneficial for the learners to continue to learn even after they have completed their formal study of target language. Brown (2006) mentions that learning strategies deal with the receptive domain of intake memory storage and recall. This means that learning strategies greatly contribute to the development of the communicative competence of the students. Oxford (1990) states language learning strategies are tools for active self-directed movement, which is essential for developing communicative competence. Simek (2006) argues that learning strategies are used to refer to all strategies that foreign language learners use in learning the target language, that is, they are the bases for any kinds of competence in foreign language. Jimenez's (2018) research reveals that learning strategies could also be used by bad language learners trying to become more successful in language learning. Language learning strategies enable the learners to achieve academic success if they are self regulated, self motivated and self directed. They also make learners use language in different situation.

Among the various learning strategies, Kikas and Jogi (2015) assert that the most basic learning strategy is cognitive rehearsal which focuses on repeating information in order to memorize the item without transforming or moving beyond what is being taught and they(2015) further concede that the most complex learning strategies are elaboration and organization. In elaboration, learners build connections between information being taught and the information located in other sources along with summarizing and paraphrasing them. On the other hand, in organization, they group or order the information, outline the most important ideas or create tables and figures. Duncan and McKeachie's (2005) research shows that students who report using elaboration and organization strategies are more able to link information from different sources ( as cited in Braten \& Stromso, 2011).

The aforementioned literature declares that learning strategies are unique, context, content and learner specific. A good language learner has to find out his/her way taking the charge himself/herself. To get mastery over any language and make the success of learning strategies, language learners need to be dedicated, directed, motivated and capable of using a wide variety of language learning strategies appropriately in the context.

In the context of Nepal, English language has been taught or learned as foreign language form basic to advanced level, that is English has become the subject of teaching and learning either as core subject or optional subject from Nursery class to advanced Ph. D. degree. Students' motivation and eagerness towards English language has been rapidly increasing. In this backdrop, the present research aims to explore the perception and practices of learning strategies employed by the learners in English language learning using the learning strategies principles developed by Rubin (1987), Oxford (1990) and Simsek (2006). 


\section{Methodology}

In this study, I used descriptive phenomenological qualitative research design. Van (1990) concedes that phenomenological research seeks understanding of the meaning and significance of a particular phenomenon as it is lived (as cited in Diaz, 2015). Similarly, Willis (2007) asserts that phenomenology allows the researcher to focus on subjective and multiple realities (as cited in Campbell, 2015, p. 288). In this study, I took learning strategies as phenomena and aims to explore the perception and practices of them by the students in learning English language in the classroom. I used in-depth interview and observation as the tools of data collection. The research was conducted in a classroom with 48 students of Bachelor of education first year majoring in English at a constituent campus under Tribhuvan University, Nepal. Both the class and campus were selected purposively. For collecting data, I observed 30 face-to-face classes as participant as well as teacher and problem provider/generator. Each day observation note focusing on learning strategies that learners employed to deal with the various aspects of language and language skills and cope with the problems generated by their teacher was noted / prepared. After observing 30 classes, all thirty notes were analyzed, compared and the list of strategies that learners used in learning English language was prepared. Then, to validate the learning strategies and find out students' perception and motivation in learning strategies and English language, 10 students from the same class were selected for interview purposively. They were interviewed in a convenient time and place both for the researcher and the participants. The interview was recorded and later it was transcribed, coded and analyzed. The study was delimited to explore the learning strategies used in learning English language aspects (Vocabulary, Grammar and Language function) and language skills( Listening, Speaking and Reading). Since the students were engaged in various reading texts, listening and speaking activities throughout the month of study as per their syllabus, writing skill was not included in this research.

Finally, the data collected from both the sources were triangulated, interpreted and analyzed descriptively.

\section{Results and Discussion}

The study explored what learning strategies students use in learning English language skills and aspects and their perception and motivation towards learning strategies and English language. The results are the culmination of the students' practices and voices and share a deep perspective into their lived experiences. To study the learning strategies employed by the learners in learning English language, I focused my research around two primary questions:

- To what extent are the students familiar and motivated to the concept of learning strategies and English language respectively?

- What strategies do they employed to learn English language aspects and skills?

First, I clearly identified the phenomenon then, elicited the participants' perspectives and practices by coding, reading and categorizing them. The accumulative description provided me to identify and describe it under language aspects and skills. 


\section{Students' Perception and Motivation towards Learning Strategies and English Language}

The literature on learning strategies suggests that learning strategies are the tactics that an individual employs to get mastery or control over his/her own learning process. All the informants were familiar with the concept of learning strategies. They conceded that learning strategies are the procedures or the activities that they use in learning language or any other thing. At the same time, they were found to be familiar with different types and levels of strategies employed in learning English language. They responded that some of them could learn better by studying tables, videos, film with English subtitles, some enjoyed learning with games, workshops, from teachers' guidance and feedback. They further added that some of them learned better by reading books, magazines, asking and sharing to each other, elaborating and explaining or listening audio songs, audio books, etc. Their accounts reveal that the informants were seemed to be very careful and aware of learning strategies and their use in learning English language.

The data further reveals that all the informants had clear purpose for learning English. Twelve of the participants stated that they knew the usefulness of English language and the various opportunities on it motivated them towards learning it. They expressed that they had keen interest and high eagerness towards learning English language. This account reveals Simek's (2006) ideas on motivational strategies in which learners develop their internal interest and manage time themselves for learning. Thirteen of the participants believed that learning English could enhance their better professional and career development. Sharing the viewpoints in this context, P1 conceded:

Well, my motivation is being able to see, read and understand articles, books or any readings and materials in English. Furthermore, I am motivated to talk to foreigners, and my colleagues and teachers in English, to listen to music and watch English film and understand them and overall to achieve sound level of English proficiency so that I could get scholarship in English speaking countries.

In the same vein, P2 added that he was learning English because it has open the doors and would provide betterment for future. It would be useful for him throughout his career and for his future professional life.

These accounts reveal that the informants had intrinsic as well as extrinsic motivation towards learning English which reflect Simek's (2006) view that conscious effort and attention of the learners towards learning enhances their motivational strategies which could be vary from learners to learners.

\section{Learning Strategies in Vocabulary Learning}

Vocabulary is a set of lexical items in the language. It includes learning word meaning in context, word use, word formation and word grammar in the language. All the participants responded that vocabulary is the core of language which beautifies the standardization of the language. Realizing this fact, they employed various strategies to learn them. In this context, P10 stated:

I listened my teacher, read the text, make list of words, used them in sentences, and sometimes memorized them. When one technique could not work I shifted into next. I evaluated myself and selected the appropriate strategy which could be matching, rearranging, making mental map, 
analyzing or elaborating to meet my capability.

In the same vein, P7 stated that he learned vocabulary by listening English songs and watching English movie. He further added that he listened the words and guessed the contextual meaning on the basis of their use. Sometimes, he talked to his friends to get the appropriate meaning.

The abovementioned discourses reveal that participants used auditory, visual, analytical, rehearsal, elaboration, organization and metacognitive strategies to learn English vocabulary. This gives a sense that no single strategy is enough and complete in learning vocabulary in English language.

\section{Strategies Employed in Leaning English Grammar}

Grammar is a set of rules in a language which governs the words, their combination and form in a meaningful manner. All the participants felt difficulty in learning grammatical rules and their uses in English language. They responded that the exceptions remain in the core rule made them difficult to learn English grammar however; they employed elaborative, organizational, cognitive and metacognitive strategies to deal with grammar in English. One of the participants P6 shared his strategies of learning grammar as:

When I learned the core rule of grammar, I tried to use it in my own sentences and context. I elaborated the same rule into a text/passage, asked my teacher to look and receive feedback which made me feel a bit competent in learning English grammar.

Similarly, P9 conceded that she was very conscious of using English grammar. She evaluated her own grammatical performance before she used it. She checked it in many other examples, be sure on it and only used it in her performance.

These two accounts reveal two different strategies that the learners employed. P1 felt comfort in elaboration strategies while P5 in metacognitive strategy. The first account reflect Kalati's (2016) ideas that language can be learned employed the combination of various techniques while the later account reflect learning strategies are the use of conscious and semiconscious capability or efficiency in building knowledge in language (Kalati, 2016).

Talking about the learning strategies employed in grammar learning, P8 conceded:

I employed receiving and restructuring technique. In this technique, I searched for alternatives, that is If I felt unsure in one structure, I found the alternatives working in the same context and employed it in learning.

This discourse reveals the participants' ability in using organizational strategies. From the aforementioned discourses, it is revealed that learners felt difficulty in learning and choosing appropriate learning strategies in grammar learning. They did not shifted from one to another or they do not mix various strategies to learn the same grammatical structure as they did in learning vocabulary.

\section{Tactics in Learning Language Functions}

Language functions are the utterances which are used to perform a purpose that is they are the ways of doing. They are the purposes of an individual for which particular utterance is used. In the study, the participants were asked low they get mastery over various communicative language functions in which 
all of them agreed that learning through dialogue and conversation among themselves were the common strategies that they employed in learning English language functions. Sharing the strategies in learning English communicative language function P4 expressed:

I learned language function through pair work and group work in which I worked with my friends engaging in pattern practice, and creating short dialogue. One of us gave situation and others create proper dialogue in that given situation.

In the same backdrop, P10 added that he used his own personal cognition to make the language more polite and appropriate to the context. P3 mostly learned language functions making the matching between the exponents that she had exposed to with the contexts of her daily activities she further added that she got mastery of them by making comparison between exponents and various situations, making and writing questions, making metal images for using them.

The accounts of the informants exhibit that the participants incorporated cognitive, metacognitive, organizational strategies including group work and pair work. They further admitted that to learn language functions single strategy does not work. According to language functions and their contexts, one or more strategies need to be incorporated together. The accounts that the participants admitted reflect Rubin's (1987) communicative strategies where focus is put on conversation and contextual meaning of an utterance.

\section{Activities Employed in Fostering Reading Skill}

Reading comprehension is metal and physical processes of understanding the text and its message where the learners keep their eyes and mind in the text to grasp the particular information from it. Almost all the participants reported that they understood the text best by analyzing, inferring, comparing, reflecting, reviewing their notes, summarizing, organizing, critical analysis, interpretation and critique. These strategies were more prominent to get message from reading text. Participant 3 flashed his experience of learning strategies employed in reading text as:

I listened my teacher's explanation and elaboration, took notes, elaborated that note, I myself read the text, underlined the important ideas, extend them as the concept that I understood, shared it to my friends, compared it with them and come to the conclusion.

In the same vein, P2 mentioned the strategies that he employed as:

I became a bit critical while getting information from the reading text. I understood the text and context, generalized the knowledge into my context-if it did not work, I changed the ideas of the text to make appropriate to my context and capability.

These two accounts bring out the fact that reading comprehension requires the integration of two or more strategies together to get the message from the text. Reading comprehension incorporates all language skills and aspects so that learners used different learning strategies even in a single text. The efforts that participants employed in fostering reading skill manifested Griffiths' (2008) view that learner chooses activities comfort for them for the purpose of regulating their own language learning as per their capabilities. 


\section{Strategies Employed in Listening Skill}

Listening is an ability to recognize and understand what others' say, that is, it incorporates comprehending speaker's tone, pronunciation, grammar, vocabulary and meaning. Participants employed listening to phone message, music and sound effect, radio and television programmes, watching and listening songs and English film for enhancing their listening skill. Sharing the experience of learning strategies for developing listening skill P4 conceded that he employed listening to English songs, picking up important words and generalizing them in his context. Similarly, P3 watched English serial without subtitle in Youtube while P9 used watching movie and following the speech of the characters for developing pronunciation and listening skill. Almost all the participants reported that they devoted very short time to strengthen their listening skill. They reported that they felt difficulty in selecting appropriate learning strategy for developing listening skill. The informants' viewpoints reveals Jimenez's (2018) research finding where university students mostly felt difficult to get mastery over listening skill due to poor listening exposure.

\section{Strategies Employed in Speaking Skills}

Speaking is being able to produce an utterance with correct phonemes, appropriate stress and intonation in connected speech. The data reveals that the participants mostly employed describing, finding differences, telling stories, summarizing, comparing, questioning and answering, reflecting self experiences, loud reading, presenting papers by taking part in workshop, training, seminar, practicing dialogues and role playing as the common strategies employed for developing their speaking skill. All the participants reported that speaking and communicating in English was a great challenge for them however, they employed various strategies consciously considering the phonological and suprasegmental rules and accuracy to make their speech free from mistakes. Sharing learning strategy experience in developing speaking skill, P7 explained:

My friends disliked talking in English except English classes. Being risky and odd I used to talk in English. I described my friends and myself in English. I shared my childhood experiences in English which attracted my friends towards speaking in English. We organized a mini conference on 'English only English' where we presented papers and commented on them. This event became landmark for improving speaking skill.

This account reveals the shift of students from non-English speaking to English speaking environment employing the strategy of risk taking, motivating, metacognitive and elaborative. In the same vein, $\mathrm{P} 2$ conceded that he frequently practiced loud reading, describing time, places, animals and things for fostering his speaking skill. Likewise, P1 took part in English drama for developing speaking skill while P8 frequently asked questions to the teachers and responded the teachers' questions.

All these accounts reflect that learners learned speaking in English language by using several learning strategies. Their sharing relates Ecclestone's (2004) claimed that if learners integrate different learning style, they will feel better and more comfort while speaking in English (as cited in Jimenez,2018, p. 76). 


\section{Conclusion and Implications}

Language learning strategies which are individual, context and content specific play significant role in a successful language learning process. Whatever the background learners are, they employed one or more learning strategies for fostering their capabilities in learning second/foreign language. This study showed that all the participants were aware and familiar with the basic concept and use of learning strategies in second/foreign language learning process. They were found to be using one or more activities to cope with the language skills/aspects that they were encountered with in classroom learning.

The accounts of the learners in the study shows that learners could not make the use of two or more activities or could not shift from one to another while learning English language grammar as it has many exceptional cases and listening skill due to their less effort and time devotion which they did in learning other aspects and skills. Similarly, the study also reflected that the participants felt more difficult to select and use the proper techniques in learning grammar than the others. The common strategies they employed in learning English were rehearsal, organization, metacognition, elaboration, visual, audio and communicative. This study encourages the learners to use tricks or techniques which fit to the context, content and their ability. At the same time, it has made the teachers aware of various learning strategies by which s/he could set up appropriate teaching strategies to make a successful language teaching. It has opened the doors for textbook writers, curriculum designers, planners and policy makers to adopt and include appropriate instructional strategies that fit the learners' interest, levels and capabilities.

\section{References}

Braten, I., \& Stromso, H. (2011). Measuring strategic processing when students read multiple texts. Metacognition and Learning, 6, 111-130.

Brown, H. D. (1994). Principles of language learning and teaching. New Jersey : Prentice Hall.

Brown, H. D. (2006). Principles of language learning and teaching $\left(5^{\text {th }}\right.$ ed. $)$. New Jersey : Prentice Hall.

Campbell, T. A. (2015). A phenomenological study on international doctoral students' acculturation experiences at a US university. Journal of International Students, 5 (3), 285-299.

Díaz, M. P. (2015).Phenomenology in educational qualitative research: Philosophy as science or philosophical science? International Journal of Educational Excellence, 1 (2), 101-110

Griffiths, C. (2008). Lesson from good language learners. Cambridge: Cambridge University Press.

Gu, P. J. (2005). Learning strategies: Prototypical core and dimensions of variation. China: Nanyang Technological University National Institute of Education Center for Research in Pedagogy and Practice.

Harmer, J. (2008). How to teach English. London: Longman.

Hismanoglue, M. (2000) Language learning strategies in foreign language learning and teaching. The Internet TESL Journal, 6 (8).

Jimenez, P. K. (2018). Exploring students' perception about English learning in a public university. HOW, 25(1), 69-91.Retrieved from https://doi.org/10.19183/how.25.1.385. 
Kafadar, T. (2013a). Examination of multiple variables of learning strategies used by students in social studies lessons (unpublished master dissertation). AhiEuran University, Turkey.

Kalati, E. A. (2016). Learning strategies in second language acquisition. Research \& Reviews: Journal of Educational Studies, 2 (4), 4-8.

Kikas, E., \& Jogi, A. L. (2015). Assessment of learning strategies: Self report questionnaire or learning task. European Journal of Psychology of Education. Retrieved fromhttps://www.researchgate.net/ publication/284798852.

Larsen Freeman, D. (2008). Techniques and principles in language teaching. Oxford : Oxford University Press.

Oxford, R. L. (1990). Language learning strategies: What every teacher should know. New York: Newbury House.

Richards, J., Platt, J., \& Platt, H. (1992). Longman dictionary of language teaching and applied linguistics. London : Longman.

Rubin, J. (1987). What the good language learners can teach us. TESOL Quarterly, 9, 41-51.

Simsek, A. (2006). Bilisselstrategilerinogretimi [Teaching Learning Strategies]. In Simsek, A. (Ed.). Icerikturlerinedayaliogretim (pp. 181-208). Ankara: Nobel.

Simsek, A., \& Balaban, J. (2010). Learning strategies of successful and unsuccessful university students. Contemporary Educational Technology, 1 (1), 36-45.

Stern, H. H. (1992). Issues and options in language teaching. Oxford : Oxford University Press.

Tay, B. (2013). Elaboration and organization strategies used by prospective class teachers while studying social studies education textbooks. Eurasian Journal of Educational Research, 13 (51), 229-252.

Pitambar Paudel is a Lecturer of English Education at Tribhuvan University, Nepal. To his credit, about three dozens of articles have been published in different national and international journals. He has also published books, edited journals and presented papers in various conferences and facilitated different training sessions in English Language teaching. His areas of interests include applied linguistics, research methodology, translation studies, research on SLA and English Language curricula, Teacher professional development and ICT in language education. 